\title{
Psychological stress and colitis
}

Qiu BS, Vallance BA, Blennerhassett PA, Collins SM. The role of CD4+ lymphocytes in the susceptibility of mice to stress-induced reactivation of experimental colitis. Nat Med 1999;5:1178-82.

\section{Abstract}

Idiopathic inflammatory bowel disease is a chronic relapsing condition. The role of stress in causing relapses of inflammatory bowel disease remains controversial. We now show that colitis induced in mice by dinitrobenzenesulfonic acid (DNBS) resolves by 6 weeks, but can subsequently be reactivated by stress plus a sub-threshold dose of DNBS, but not by DNBS alone. Stress reduced colonic mucin and increased colon permeability. Susceptibility to reactivation by stress required CD4+ lymphocytes and could be adoptively transferred. We conclude that stress reactivates experimental colitis by facilitating entry of luminal contents that activate previously sensitized CD4 cells in the colon.

\section{Comment}

In cardiovascular disease, the role of stressful life events, personality profiles, and affective disorders as risk factors for the development of morbidity and mortality from established coronary artery disease is well established. ${ }^{1}$ Furthermore, specific biological mediators of these psychosocial factors, such as reduced cardiovagal tone and altered platelet function have been identified. ${ }^{2}$ In contrast, the role of psychosocial factors in the development and modulation of common gastrointestinal disorders, such as functional and inflammatory bowel disorders and gastrooesophageal reflux disease remain controversial. This is particularly surprising in view of the unique well established bidirectional interactions between the brain and gut, the prominent role of the gut associated lymphoid tissue in this brain-gut interaction, and in view of the common clinical impression that certain stressful life events frequently precede exacerbation of symptoms in all of these disorders. However, recent breakthroughs in our understanding of the neurobiology of the stress response both under acute conditions and in the setting of chronic stress provide a framework for scientific investigation which allow us to move from the traditional psychological and epidemiological domain into the biological interface between mind, brain, and gut function. ${ }^{3}$ The article by Qiu and colleagues ${ }^{4}$ is a good example of this new approach to unravelling the role of stress in disorders of the gut.

Evidence for a role of chronic stressors in the modulation of disease activity in inflammatory bowel disease (IBD) comes from three different sources: epidemiological studies in IBD patients, "naturalistic" stress studies in animals, ${ }^{56}$ and mechanistic studies on neuroimmune interactions. ${ }^{78}$ Two large, prospective studies ${ }^{9}$ have clearly demonstrated the increased risk of IBD symptom exacerbation following severe, sustained life stresses. The lack of correlation between life events and disease activity reported in other studies may be related to small sample sizes and differences in the assessment of relevant psychosocial stressors. For example, recent studies on the relationship of life events with functional gastrointestinal symptoms have emphasised that it is only the severe, sustained, and threatening events which show significant correlations with symptoms. ${ }^{10}$

Stressful life events, regardless of whether or not they are consciously perceived by the organism, represent a threat to the homeostasis of the organism and trigger a physiological response of the autonomic, neuroendocrine, and antinociceptive systems aimed at adaptation and survival in the short run. However, the same response systems can cause damage and exacerbate disease processes over longer periods of time. ${ }^{11}$ Stress responses can be triggered by systemic stressors such as visceral inflammation, cold temperature, or haemorrhage, or by neurogenic stressors such as threatening life events or pain. ${ }^{12}$

A network comprised of integrative brain structures, in particular subregions of the hypothalamus, amygdala, and periaqueductal grey provide outputs to the pituitary and to pontomedullary nuclei, which in turn mediate the neuroendocrine and sympathoadrenal output to the body, respectively. ${ }^{12-14}$ This central stress circuitry is under feedback control via ascending projections from these brainstem nuclei, in particular serotonergic (raphe nuclei) and noradrenergic (locus coeruleus) nuclei, and via circulating glucocorticoids, which exert an inhibitory control via central glucocorticoid receptors. ${ }^{15}$ Forebrain structures, such as the medial prefrontal cortex, play a prominent role in cortical modulation of the stress circuits. The responsiveness and output pattern of this network is likely to be under partial genetic control and shows considerable plasticity in response to early life events ${ }^{16}$ and to chronic stress. ${ }^{17}{ }^{18}$ For example, studies in animals and humans have clearly demonstrated that certain types of sustained, chronic stressors can alter the responsiveness of feedback systems by downregulation of receptors (adrenergic, serotonergic, glucocorticoid receptors $)^{17} 18$ and in the most severe forms by structural changes in certain brain regions. ${ }^{19-21}$ Thus chronic stress can fundamentally change the responsiveness and output to the periphery of the central stress circuits.

Despite the integrated nature of the response to different stressors, there is considerable variability in the specifics of the peripheral output. For example, 12 different functional groups of sympathetic neurones have been identified. ${ }^{22}$ Some of these pathways regulate mucin production by large intestinal goblet cells, ${ }^{23}$ others mucosal permeability, ${ }^{24}$ and others have a direct immunomodulatory function. ${ }^{7}$ Evidence has been provided to suggest that there is a functionally distinct branch of the sympathetic nervous system dedicated specifically to immune modulation. $^{22}$

Qiu and colleagues ${ }^{4}$ have provided evidence that short term moderate stress can enhance the response of the colon to chemically induced inflammation. Their findings are consistent with a model in which the effect of the stressor is primarily mediated by autonomic responses, and not by stress induced changes in neuroendocrine function 
(HPA axis). The authors show that CD4+ cells which are sensitised by a chemically induced colitis can be reactivated by a subthreshold dose of the same chemical irritant applied to the colon six weeks after the initial insult, at a time of complete mucosal healing. They provide evidence that this effect requires sensitised CD4+ lymphocytes, and is mediated in part by an effect of the stressor on mucin production and colon permeability, presumably facilitating access of the irritant to the sensitised lymphocytes.

Even though this study represents an important step in our understanding of the mechanisms operating at the biological interface between life events and gastrointestinal mucosal inflammation, many questions remain unanswered: (1) What was the role of the chronic colitis itself on the responsivity of the central stress circuits? For example, recent evidence suggests that chemically induced colitis in the rat results in alteration in hypothalamic corticotrophin releasing hormone (CRF) expression and blunting of the HPA axis (Y Tache, personal communication). (2) Is the stressor used in this study an adequate representation of the sustained, chronic threatening life event thought to be important in the modulation of human colitis? For example, in response to acute experimentally induced stressors, sympathetic nervous system responses appear to mediate a transient increase in natural killer cell number and activity which may represent an integral part of the body's adaptive "fight and flight" reaction. In contrast, chronic naturalistic stressors can be associated with a decrease in immune function..$^{25}$ Is the same effect seen with other types of stressors of different duration and severity? Were there other direct effects of sympathetic neurones on gut associated immune cells?

The answers to these specific questions will help to better understand neuroendocrine and immune interactions in the gut, and at the same time enable us to design more definitive studies in the clinic on the role of stress and inflammatory bowel disease.

E A MAYER

UCLA/CURE Neuroenteric Disease Program, UCLA Division of Digestive Diseases,

Los Angeles, CA 90024, USA

Correspondence to:

GLA VA Healthcare System, 11301 Wilshire Boulevard, Building 115, Room 223, Los Angeles, California 90073, USA (Email: emayer@UCLA.edu)

1 Musselman D, Nemeroff CB. Depression really does hurt your heart: stress, depression, and cardiovascular disease. In: Mayer EA, Saper CB, eds. The biological basis for mind body interactions, vol. 122. Amsterdam: Elsevier Science, 2000:43-59.

2 Verrier RL, Mittleman MA. The impact of emotions on the heart. In: Mayer EA, Saper CB, eds. The biological basis for mind body interactions, vol. 122. Amsterdam: Elsevier Science, 2000:369-80.
3 Mayer EA, Saper CB, eds. The biological basis for mind body interactions. Amsterdam: Elsevier, 2000

4 Qiu BS, Vallance BA, Blennerhassett PA, Collins SM. The role of CD4+ lymphocytes in the susceptibility of mice to stress-induced reactivation of experimental colitis. Nat Med 1999;5:1178-82.

5 Wood JD, Peck OC, Tefend KS, et al. Colitis and colon cancer in cotton-top Tamarins (Saguinus oedipus oedipus) living wild in their natural habitat. Dig Dis Sci 1998;43:1443-53.

6 Stout C, Snyder R. Ulcerative colitis-like lesions in Siamong gibbons. Gastroenterology 1969;57:256-61.

7 Felten DL. Neural influence on immune responses: underlying suppositions and basic principles of neural-immune signaling. In: Mayer EA, Saper CB, eds. The biological basis for mind body interactions, vol. 122. Amsterdam: Elsevier Science, 2000:381-9.

8 Sternberg EM. Interactions between the immune and neuroendocrine systems. In: Mayer EA, Saper CB, eds. The biological basis for mind body interactions, vol. 122. Amsterdam: Elsevier Science, 2000:35-42.

9 Duffy LC, Zielezny MA, Marshall JR, et al. Relevance of major stress events as an indicator of disease activity prevalence in inflammatory bowel disease. Behav Med 1991;17:101-10.

10 Bennett EJ, Tennant CC, Piesse C, Badcock C-A, Kellow JE. Level of chronic life stress predicts clinical outcome in irritable bowel syndrome. Gut 1998;43:256-61

11 McEwen BS. Protective and damaging effects of stress mediators. $N$ Engl $\mathcal{F}$ Med 1998;338:171-9.

12 Sawchenko PE, Li H-Y, Ericsson A. Circuits and mechanisms governing hypothalamic responses to stress: a tale of two paradigms. In: Mayer EA, Saper CB, eds. The biological basis for mind body interactions, vol. 122 . Amsterdam: Elsevier Science, 2000:61-78.

13 LeDoux JE. The emotional brain: the mysterious underpinnings of emotional life. New York: Simon and Schuster, 1996.

14 Bandler R, Price JL, Keay KA. Brain mediation of active and passive emotional coping. In: Mayer EA, Saper CB, eds. The biological basis for mind body interactions, vol. 122. Amsterdam: Elsevier Science, 2000:333-49.

15 Sternberg EM, Chrousos GP, Gold PW. The stress response and the regulation of inflammatory disease. Ann Intern Med 1992;117:854-66.

16 Ladd CO, Huot RL, Thrivikraman KV, et al. Long-term behavioral and neuroendocrine adaptations to adverse early experience. In: Mayer EA, Saper CB, eds. The biological basis for mind body interactions, vol. 122. Amsterdam: Elsevier Science, 2000:81-103.

17 Fuchs E, Fluegge G. Modulation of binding sites for corticotropin-releasing hormone by chronic psychosocial stress. Psychoneuroendocrinology 1995;20: 33-51.

18 Fluegge G. Alterations in the central nervous alpha 2-adrenoceptor system under chronic psychosocial stress. Neuroscience 1996;75:187-96.

19 Bassotti G, Betti C, Fusaro C, Morelli A. Colonic high-amplitude propagated contractions (mass movements): repeated 24-h manometric studies in healthy volunteers. F Gastrointest Motility 1992;4:187-91.

20 Bremner JD, Randall P, Vermetten E, et al. Magnetic resonance imaging-based measurement of hippocampal volume in posttraumatic stress disorders related to childhood physical and emotional abuse-a preliminary report. Biol Psychiatry 1997;41:23-32.

21 Fuchs E, Uno H, Fluegge G. Chronic psychosocial stress induces morphological alteration in hippocampal pyramidal neurons of the tree shrew. Brain Res 1995;673:275-82.

22 Jaenig W, Habler H-J. Specificity in the organization of the autonomic nervous system: a basis for precise neural regulation of homeostatic and protective body functions. In: Mayer EA, Saper CB, eds. The biological basis for mind body interactions, vol. 122. Amsterdam: Elsevier Science, 2000:351-67.

23 Furness JB, Costa M. Sympathetic influences on gastrointestinal function. In: The enteric nervous system, vol. 9. New York: Churchill Livingstone, 1987:207-38.

24 Santos J, Saunders PR, Hanssen NP, et al. Corticotropin-releasing hormone mimics stress-induced colonic epithelial pathophysiology in the rat. $A m \mathcal{F}$ Physiol 1999;277:G391-3.

25 Kemeny ME, Gruenwald TL. Affect, cognition, the immune system and health. In: Mayer EA, Saper CB, eds. The biological basis for mind body interactions, vol. 122. Amsterdam: Elsevier Science, 2000:291-308. 